\title{
STABILISATION AND DEVELOPMENT OF THE HIP AFTER CLOSED REDUCTION OF LATE CDH
}

\author{
HÅKAN DAHLSTRÖM， SVEN FRIBERG， LARS ÖBERG
}

From the University Hospital, Umeå

\begin{abstract}
We used ultrasound to investigate the anatomy and stability of the hip during the phase of joint stabilisation after closed reduction of unilateral late CDH in 15 infants aged from two to 15 months. Conservative treatment by splintage in abduction led to complete stability in all hips in from three to 13 weeks. Immediately after reduction, interposed soft tissue caused lateralisation of the femoral head, but this progressively disappeared, and the initially smaller femoral head on the dislocated side regained normal size.

Ultrasonic evaluation of the hip in late CDH is a valuable and safe tool; it reduces the need for radiographic examination and improves treatment by visualising the actual pathology. The more frequent use of ultrasound can reduce the need for open reduction in the age group that we studied.
\end{abstract}

After the late diagnosis of congenital dislocation of the hip (late CDH), treatment is controversial. Leveuf (1948) was an advocate of open reduction, stating that closed treatment could never be successful in complete late CDH. More recently Ferguson (1973) and Diepstraten (1985) also have recommended open reduction, but Kalamchi, Schmidt and MacEwen (1982) reported a high incidence of postoperative complications. On the other hand, closed reduction and conservative treatment have been shown to provide some excellent results (Visser 1984; Friberg et al 1986; Zionts and MacEwen 1986).

As early as 1950 Severin used arthrography to investigate the hip after the closed reduction of late $\mathrm{CDH}$. He recommended conservative treatment for the majority of cases and considered that the findings on an immediate post-reduction arthrogram should not be an indication for open reduction. The recent introduction of ultrasound for the investigation of the hip in infants has provided a harmless tool, which is superior to arthrography and CT scans for the investigation of late CDH (Ahlgren and Friberg 1983; Clarke 1986; Dahlström, Öberg and Friberg 1986; Dahlström et al 1986; Graf 1986).

H. Dahlström, MD, Orthopaedic Surgeon

S. Friberg, Professor and Head, Department of Orthopaedics

L. Oberg, MD, Radiologist

University Hospital, S-90185, Umeå, Sweden

Correspondence should be sent to Dr H. Dahlström.

(C) 1990 British Editorial Society of Bone and Joint Surgery

$0301-620 X / 90 / 2024 \$ 2.00$

J Bone Joint Surg [ Br] 1990; 72-B : 186-9.
We consider the orthopaedic management of late $\mathrm{CDH}$ in four phases: diagnosis, reduction, stabilisation, and remodelling to restore delayed skeletal development. We have used sonography to study the effect of conservative treatment on the anatomy and stability of the hip during the phase of stabilisation.

\section{PATIENTS AND METHODS}

We investigated the hips of 15 consecutive infants with unilateral late $\mathrm{CDH}$ (one male) diagnosed at two to 15 months (median five, mean eight). The hips were examined with ultrasound at two to three weekly intervals after reduction of the dislocation and until the joints were stable to manual provocation.

Diagnosis. The diagnosis was confirmed clinically and by ultrasound and radiography. The 13 fixed dislocations were easily identified on static sonograms, which showed an empty acetabulum with the femoral head lying craniodorsal to the socket. The other two infants, aged two and six months, had positive Ortolani signs, and the dislocations were visualised during dynamic sonography with manual provocation. An anteroposterior radiograph was taken once on admission to visualise the acetabular slope and was not repeated until complete stabilisation and joint congruency had been obtained.

Reduction. Seven infants (mean age 8.3 months) were treated initially by traction and six (mean age nine months) were splinted in the Malmö (von Rosen) splint with increasing abduction until reduction was possible by gentle manipulation. In the two infants with a positive 
Ortolani sign on admission, the hips were easily reduced during the diagnostic examination. In all hips, reduction was confirmed by ultrasonography.

Stabilisation. After reduction the children were splinted without force in a position shown to be stable during the ultrasound examination, usually in abduction of $70^{\circ}$ to $80^{\circ}$ and flexion of $100^{\circ}$ to $120^{\circ}$ (Dahlström and Friberg 1987). It is essential that forced positions are avoided to prevent avascular necrosis of the femoral head. During this period, as intrinsic joint stability increased, the

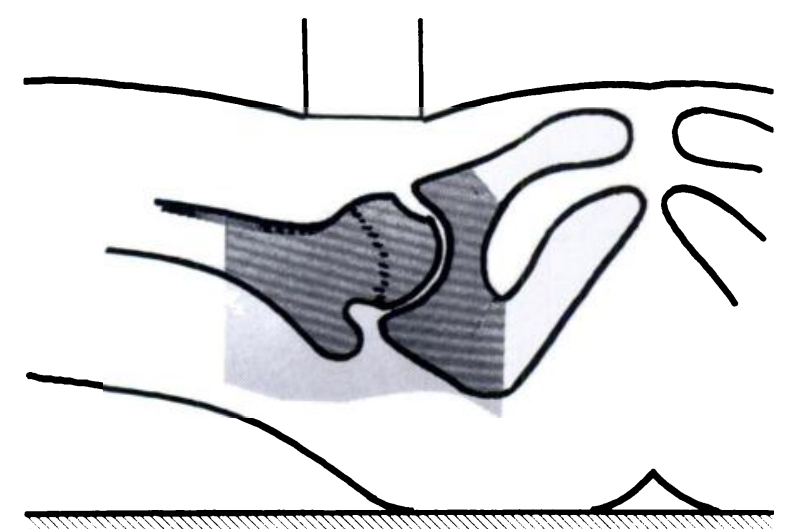

Fig. 1

Diagram of the ultrasonic projection. amount of flexion was decreased and flexion movements were allowed between $80^{\circ}$ and $100^{\circ}$.

Ultrasonic investigation. The ultrasonic investigation was performed with a $7.5 \mathrm{MHz}$ transducer, using gel as couplant, connected to a real-time ultrasonic sector scanner. Infants were investigated in the 'frog position', that is with flexion and abduction of the hip. The probe was applied to the groin, and the sound-sector oriented parallel to the femoral neck. This projection produces a sonogram equivalent to an anteroposterior view of the femoral head and neck and a lateral view of the acetabulum (Fig. 1). Joint stability was evaluated by ultrasound during the Barlow manoeuvre (1962). These investigations were performed jointly by a radiologist and an orthopaedic surgeon who performed the manipulations. All examinations were documented on film and video tape.

\section{RESULTS}

Acetabulum. Immediately after reduction, soft tissues could be visualised between the acetabular socket and the femoral head in 14 of the 15 infants. These soft tissues prevented congruency by producing lateralisation of the femoral head in relation to the acetabulum (Fig. 2). In one child, aged seven months, no lateralisation was found after reduction.

Immediately after reduction the mean lateralisation was $5.5 \mathrm{~mm}$ (range 0 to 8 ). The size of the soft tissue

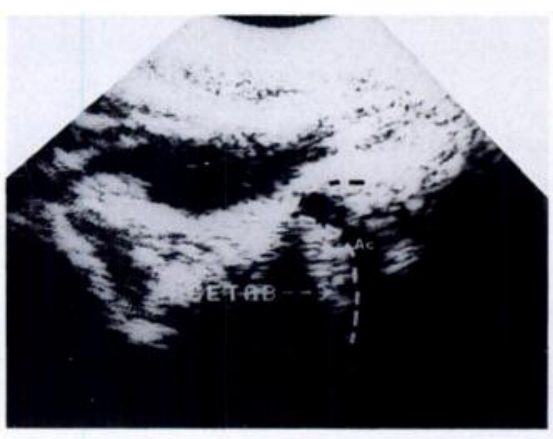

Fig. 2a

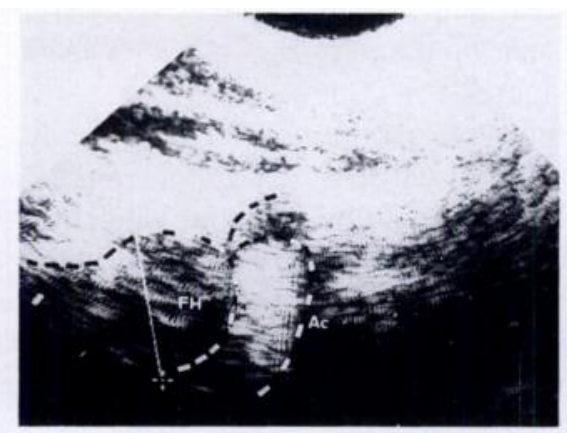

Fig. 2b

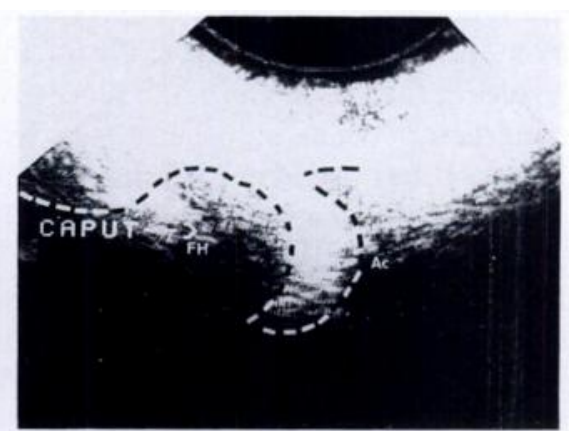

Fig. 2c

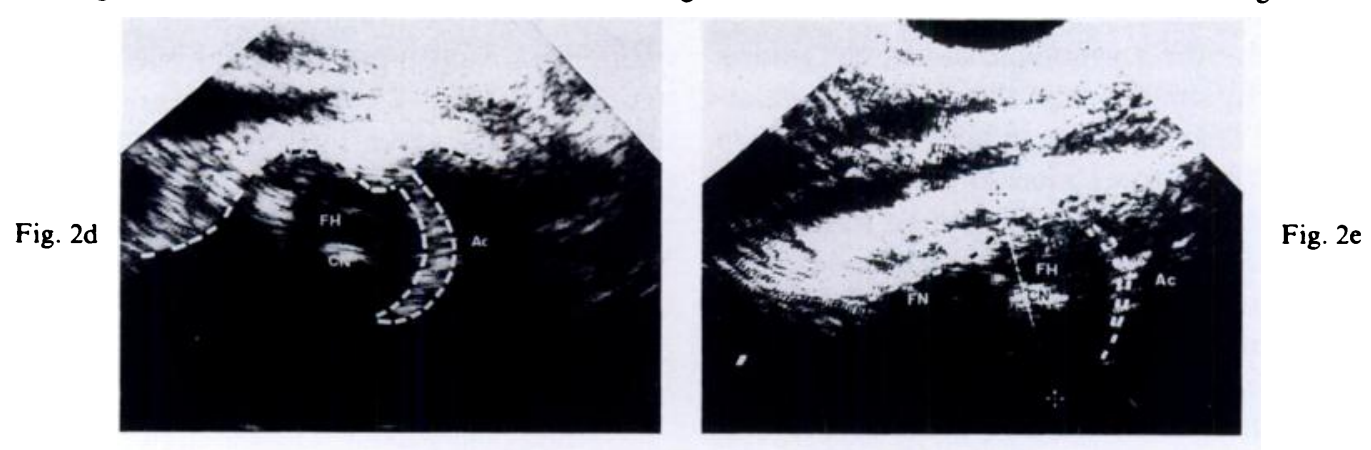

Ultrasonograms of an eight-month-old girl diagnosed as having a fixed congenital dislocation of her right hip. Figure 2a - At diagnosis showing the empty acetabulum (Ac). Figure $2 b$ - Immediately after reduction the joint is not congruent (FH) femoral head. Figure $2 c-$ Three weeks after reduction there is increased congruency and slightly less lateralisation of the femoral head. Figure $2 \mathrm{~d}-\mathrm{Six}$ weeks after reduction there is a definite decrease in lateralisation of the femoral head and a calcified nucleus $(C N)$ has appeared. Figure $2 e-N i n e$ weeks after reduction the joint space is normal and the joint is stable (FN) femoral neck. 
obstruction diminished during successive examinations: the lateral position of the head had totally resolved in all cases within 16 weeks (Fig. 3). The spontaneous disappearance of interposed tissue and concomitant increase in joint congruency in one of the infants is illustrated in Figures 2a to 2e.

Femoral head. At diagnosis the dislocated head was always smaller by $1 \mathrm{~mm}$ to $5 \mathrm{~mm}$ than the femoral head on the normal side $(\mathrm{p}=0.001$, Student's $t$-test). The mean diameter of the dislocated head was $16 \mathrm{~mm}$ compared to $19 \mathrm{~mm}$ on the normal side. The previously dislocated head progressively increased in size; after three months of abduction treatment the mean difference was $1 \mathrm{~mm}$ (range 0 to 3 ).

Stabilisation of the joint. Full stability to manual manipulation was present ultrasonographically within three to 13 weeks (mean eight weeks). With one exception, joint stability was not present until the lateralisation of the femoral head had completely disappeared.

\section{DISCUSSION}

Our investigation showed that, after reduction of a dislocated hip, soft tissues in the acetabulum prevented full congruency of the joint. The soft tissues which produced lateralisation of the head became progressively less bulky during abduction treatment. Even a soft tissue mass of $8 \mathrm{~mm}$, seen in one infant, resolved during treatment. This agrees with the findings of Severin (1950) who demonstrated arthrographically that such lateralisation disappeared during conservative treatment. However, he was not able to evaluate the size of the soft tissues in the acetabulum; the successive increase in joint congruency could only be shown by repeated arthrograms. It has been claimed that interposed soft tissue is an obstacle to the reduction of late $\mathrm{CDH}$ and should be removed surgically (Leveuf 1948; Mau et al 1971; Ferguson 1973; Diepstraten 1985). Our results challenge this opinion and show that conservative treatment has the same effect. Lateralisation and lack of congruency at the beginning of the stabilisation phase of late $\mathrm{CDH}$ should not be considered an indication for surgery in the age group we investigated.

After reduction, the formerly dislocated femoral head was significantly smaller than that of the contralateral normal hip. Considerable catching up was seen during treatment; within three months the difference in size was insignificant. This was also studied by Severin (1950) who noticed progressive normalisation of the dysplastic head. This increase in size of the head supports the belief that normal anatomy and stability are prerequisites for normal development. It may also indicate that there is no disturbance of blood supply to the femoral head. This is, of course, speculative: but we saw no radiographic evidence of avascular necrosis in our series. Furthermore, if a definitely smaller femoral head is found on ultrasonography for suspected late $\mathrm{CDH}$, this provides more evidence for some joint pathology. Further investigation of the normal variation in diameter of the femoral head at different ages is needed.

All the infants in our series developed full stability of the hip. Complete stability to manual provocation did not occur until interposing soft tissues had disappeared and joint congruency was obtained. This implies that lateralisation of the head found during ultrasonography for suspected late CDH must always arouse a definite suspicion of joint instability.

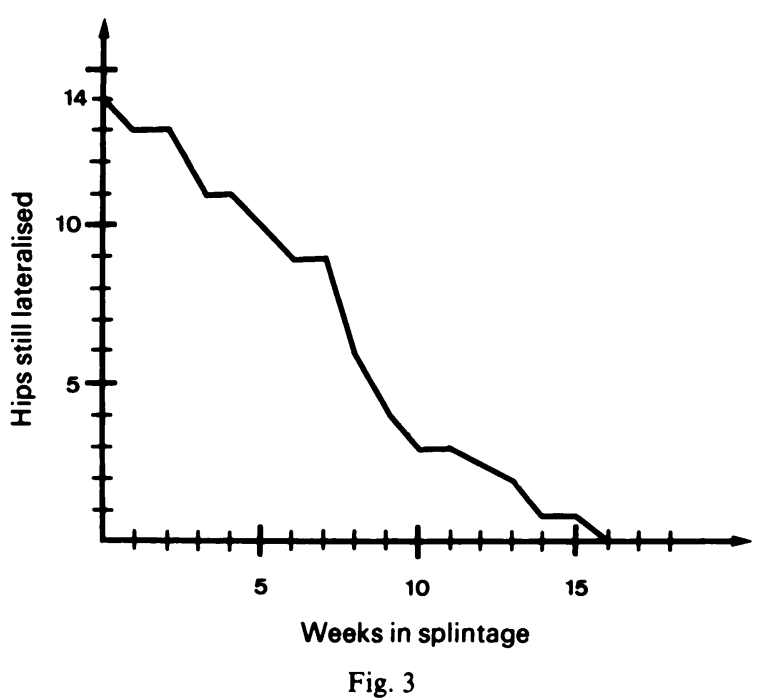

Number of hips with remaining lateralisation of the femoral head in relation to weeks in abduction splintage.

In our study, radiographic examinations were not used during the stabilisation phase, since we feel that it has no value at this stage. Ultrasonic evaluation alone can provide all the information needed for successful treatment. However, radiographic examination seems to remain mandatory for the evaluation of the development and the mineralisation of the acetabulum and femoral head during the remodelling phase.

We believe that conservative treatment can be improved with the aid of ultrasound. This may diminish or abolish the need for open reduction in younger infants with late $\mathrm{CDH}$. We feel that treating $\mathrm{CDH}$ without ultrasound is like treating fractures without radiography.

No benefits in any form have been received or will be received from a commercial party related directly or indirectly to the subject of this article.

\section{REFERENCES}

Ahlgren 0, Friberg S. Late congenital dislocation of the hip: reduction and treatment with abduction splint. Acta Orthop Scand 1983; $54: 498-9$.

Barlow TG. Early diagnosis and treatment of congenital dislocation of the hip. J Bone Joint Surg [Br] 1962; 44-B :292-301. 
Clarke NM. Sonographic clarification of the problems of neonatal hip instability. J Pediatr Orthop 1986; 6:527-32.

Dahlström H, Friberg S. Stability of the hip joint after reduction of latediagnosed congenital dislocation of the hip. J Pediatr Orthop 1987; 7:401-4.

Dahlström H, Öberg L, Friberg S. Sonography in congenital dislocation of the hip. Acta Orthop Scand 1986; 57:402-6.

Dahlström H, Öberg L, Lundström B, Friberg S. Diagnostic accuracy of ultrasound compared to radiographic assessment of the hip joint in CDH. Acta Orthop Scand 1986; 57:260.

Diepstraten FM. Open reduction of congenital hip dislocation: advantages of the Ferguson medial approach. Acta Orthop Scand $1985 ; 56: 32-5$.

Ferguson AB Jr. Primary open reduction of congenital dislocation of the hip using a median adductor approach. J Bone Joint Surg [ Am] $1973 ; 55-A: 671-89$.

Friberg S, Dahlström H, Öberg L, Lundström B. Pitfalls in abduction treatment of late discovered CDH. Acta Orthop Scand 1986; $57: 260$.
Graf R. Sonographie der Säuglingshüfte: Ein Kompendium. Bücherei des Orthopäden Band 43. Stuttgart: Ferdinand Enke Verlag, 1986.

Kalamchi A, Schmidt TL, MacEwen GD. Congenital dislocation of the hip: open reduction by the medial approach. Clin Orthop 1982: 169:127-32.

Leveuf J. Results of open reduction of "true" congenital luxation of the hip. J Bone Joint Surg [ Am] 1948; 30-A :875-82.

Mau H, Dörr WM, Henkel L, Lutsche J. Open reduction of congenital dislocation of the hip by Ludloff's method. J Bone Joint Surg [ Am] 1971 ; 53-A :1281-8.

Severin E. Congenital dislocation of the hip: development of the hip joint after closed reduction. J Bone Joint Surg [Am] 1950; 32A:507-18.

Visser JD. Functional treatment of congenital dislocation of the hip. Acta Orthop Scand 1984; Suppl 206.

Zionts LE, MacEwen GD. Treatment of congenital dislocation of the hip in children between the ages of one and three years. $J$ Bone Joint Surg [Am] 1986; 68-A :829-46. 